\title{
Comparative aspects of placental efficiency
}

\author{
M. E. Wilson ${ }^{1}$ and S. P. Ford ${ }^{2 *}$ \\ 'Division of Animal and Veterinary Science, West Virginia University, Morgantown, \\ WV 26506-6108, USA; and ${ }^{2}$ Department of Animal Science, lowa State University, \\ Ames, IA 50011-3150, USA
}

\begin{abstract}
Litter size is often proposed as the trait that could have the greatest impact in improving reproductive efficiency of pigs. Efforts to select directly for increased litter size have generally been unsuccessful and highly variable. As a result, several attempts have been made to identify critical physiological components that control litter size, with the underlying assumption that augmenting these components would improve this important trait. One attempt at improving physiological components has involved the selection of animals for increased uterine capacity, as measured by the number of fetuses or piglets that a female can carry successfully to term. Recent evidence indicates that one critical component of the uterine capacity in pigs is placental efficiency, or the body weight of a piglet divided by the mass of its placenta. It is easy to determine the average placental efficiency in a litter, but variation among conceptuses within a litter for this trait can be substantial, leading to the conclusion that placental efficiency is an individual conceptus trait. It is suggested that the limited success of selection for an increased uterine capacity results, at least in part, from a misguided view that 'uterine capacity' is strictly a maternal trait. Uterine capacity is better defined as the mass of placental tissue that a pregnant female can support to term, and involves phenotypic variation in both the dam and her offspring. This definition of uterine capacity allows maximization of both uterine size and placental efficiency in future attempts to increase litter size in pigs.
\end{abstract}

\section{Introduction}

A critical element limiting reproductive efficiency in pigs is the large number of potential conceptuses that are lost during gestation (Dziuk, 1987; Lawrence, 1993; Pope, 1994; Rohrer et al., 1999). A number of studies over the last 85 years have highlighted the impact of conceptus loss, particularly from day 12 to day 18 of gestation, on litter size (Hammond, 1914; Corner, 1923; Perry, 1954; Hanly, 1961; Perry and Rowlands, 1962; Scofield, 1972; Dziuk, 1987; Pope, 1994). In general, there is agreement that between 30 and $40 \%$ of the embryos formed are lost during this peri-elongation-attachment period (reviewed by Pope, 1994). Recent evidence indicates that embryo losses after day 18 of gestation are significant

Journal paper published with the approval of the Director of Agricultural and Forestry Experiment Station, West Virginia University as scientific paper no. 2781

*Current address: Department of Animal Science, University of Wyoming, Laramie, WY 82071-3684, USA

Email: mwilso25@wvu.edu 
and that variation in placental function may contribute to these losses (Wilson et al., 1998, 1999a, 2000). Late embryonic and early fetal losses are particularly critical in commercial crossbred sows in which the ovulation rate is very high (approximately 26 oocytes; Wilson et al., 2000). Therefore, although $30-40 \%$ of the embryos are lost between day 12 and day 18 of gestation, the number of conceptuses present at day 25 of gestation is much greater than the number of embryos that survive to term (Foxcroft, 1997; Wilson et al., 2000). In this review, recent work to elucidate the role of the conceptus in determining individual placental size and function, the role of modulation of the uterine environment in altering placental size and function, and the mechanism by which variation in placental size may influence the number of conceptuses that survive beyond days $20-25$ of gestation, is described.

Ford (1997) presented the results of nearly a decade of research comparing the prolific Meishan pig to its distant relatives, the commercial occidental breeds. The overwhelming conclusion was that the Meishan pig embryo shows a reduced growth rate during early gestation compared with that of the other breed (Youngs et al., 1993, 1994; Rivera et al., 1996; Ford, 1997; Wilson and Ford, 1997) and concomitantly shows a markedly smaller and more vascular placenta in late gestation (Ford, 1997; Biensen et al., 1998; Wilson et al., 1998). Litter size was greater in Meishan gilts as compared with Yorkshire pigs (one of the occidental breeds used for comparison) despite similar uterine size and ovulation rate (Bazer et al., 1988; Christenson, 1993; Galvin et al., 1993; Lee et al., 1995; Ford, 1997; Biensen et al., 1998; Wilson et al., 1998). Biensen et al. (1998) suggested that, in addition to the known impacts of ovulation rate or uterine size, variation in conceptus-uterine interaction must also limit conceptus survival and litter size. When both Yorkshire and Meishan embryos were cotransferred into a common uterine environment (either Meishan or Yorkshire gilts), fetat and piglet body weights at or near term were similar for the littermate Meishan and Yorkshire fetuses and piglets, despite the fact that Meishan conceptuses developed on smaller placentae (approximately $70 \%$ of the mass of the placentae of their Yorkshire littermates regardless of an overall breed-of-dam effect; Wilson et al., 1998, 1999b). This critical observation indicates that the difference observed in placental size between straight bred Meishan and Yorkshire conceptuses is not simply a result of an overall smaller conceptus, but of an apparent dissociation of placental and fetal growth (Biensen et al., 1998, 1999; Wilson et al., 1998). As a result of this apparent dissociation, the ratio of fetal or piglet body weight to placental mass (placental efficiency) was used as a measure of placental function (Ford, 1997; Wilson et al., 1999a). At farrowing Meishan conceptuses had placental efficiencies of $8.7 \pm 0.4$ and $6.3 \pm 0.5$ when gestated in Meishan and Yorkshire recipient female pigs, respectively. In contrast, Yorkshire conceptuses had placental efficiencies of $4.1 \pm 0.9$ and $3.4 \pm 0.8$ when gestated in Meishan and Yorkshire female pigs, respectively (Ford, 1997).

\section{Pattern of placental growth and function}

In general, placental growth, as measured by mass, increases exponentially between day 20 and day 60 of gestation (Pomeroy, 1960; Knight et al., 1977). The growth of the placenta then plateaus from day 60 to day 110 of gestation, and this is followed by a secondary increase immediately before term (Pomeroy, 1960; Knight et al., 1977; Biensen et al., 1998; Wilson et al., 1998). This pattern of growth emphasizes what has been observed in occidental breeds. This placental growth pattern was observed in Yorkshire pigs, but Meishan pigs have a smaller placenta throughout gestation and do not show a preterm increase in placental mass (Ford, 1997; Biensen et al., 1998; Wilson et al., 1998). Several workers have reported that placental mass does not change after day 70 of gestation; however, these authors all ceased measurement of placental mass on or before day 105 of gestation, the time of the initiation of 
the secondary increase (Knight et al., 1977; Vallet et al., 1996; Klemcke and Christenson, 1997). Data presented by Knight et al. (1977) indicate an evident increase (approximately $25 \%$ ) in placental mass between day 90 and day 100 of gestation. This increase is obscured by a relatively uncharacteristic peak in placental mass in animals killed on day 70 of gestation (Pomeroy, 1960; Biensen et al., 1998). In the study by Knight et al. (1997), a second set of animals was unilaterally hysterectomized-ovariectomized to establish a limiting uterine environment or capacity (Knight et al., 1977). In these unilaterally hysterectomizedovariectomized animals, a peak in placental mass was not observed at day 70 of gestation. However, there was a similar (approximately 25\%) increase in placental mass between day 90 and day 100 of gestation; this difference was greater than the difference in placental mass between the intact and unilaterally hysterectomized-ovariectomized animals on day 80 of gestation (Knight et al., 1977).

The surface area of the chorioallantoic membrane increases rapidly from day 35 to day 70 (Knight et al., 1977). On day 35, the surface area is approximately $250 \mathrm{~cm}^{2}$, whereas at day 70 it is approximately $1000 \mathrm{~cm}^{2}$ (Knight et al., 1977; Biensen et al., 1998). By days 60-70 of gestation, there is an interlocking network of fetal and maternal microvilli, increasing the massive exchange surface of the placenta (Friess et al., 1980; Björkman and Dantzer, 1987; Biensen et al., 1998). From day 70 to day 100 of gestation, there is little change in the surface area of the placenta (Knight et al., 1977). However, at some time after day 100 there is a marked increase in the surface area of the placenta, reaching approximately $1500 \mathrm{~cm}^{2}$ (Biensen et al., 1998), or doubling in size by day 110 of gestation (Wigmore and Strickland, 1985). The surface area for exchange is increased greatly by microscopic folding compared with that described by simply spreading out the intact chorioallantoic membrane (Björkman and Dantzer, 1987; Dantzer and Leiser, 1994; Biensen et al., 1998).

The area for contact between the chorionic ectoderm and the luminal epithelium by the folding of the chorionic membrane into the permanent folds of the endometrium is increased markedly by the development of microscopic interdigitations, referred to as primary rugae, along the feto-maternal interface at about day 35 to day 40 of gestation (Friess et al., 1980; Björkman and Dantzer, 1987; Leiser and Dantzer, 1988; Dantzer and Leiser, 1994). During the final third of gestation, the functional surface area for nutrient and waste exchange is increased further by the development of an additional tier of interdigitation along the primary rugae, referred to as secondary rugae (Friess et al., 1980; Björkman and Dantzer, 1987). These microvilli are between 0.8 and $1.0 \mu \mathrm{m}$ in length, and $0.08 \mu \mathrm{m}$ in diameter, and occur at approximately 85 per $\mu \mathrm{m}^{2}$ (Björkman, 1965).

An important component in the function of the placenta during gestation is the development of a sufficient absorptive area, not only in the physical size of the placenta, but also in the number and density of blood vessels for nutrient exchange (Friess et al., 1980; Leiser and Dantzer, 1988; Reynolds and Redmer, 1995; Biensen et al., 1998). By day 70 of gestation, the placental vasculature accounts for approximately $3.7 \%$ of the total volume of the chorioallantoic membrane (Biensen et al., 1998). The density of blood vessels remains relatively constant during late gestation and occupies $3 \%$ of chorioallantoic membrane volume by day 90 , and $2.5 \%$ of chorioallantoic membrane volume by day 110 of gestation (Biensen et al., 1998). Furthermore, Wilson et al. (1998) reported that in farrowed placentae, the vascular volume was approximately $4 \%$ of placental volume. Pigs are described as having all six potential tissue layers present between the maternal and fetal blood supplies (that is, epitheliochorial as classified by Grosser, 1933). However, the maternal and fetal capillaries for exchange can migrate towards each other, reducing the thickness of the respective epithelial layers such that the distance between endothelial cell membranes is approximately $2 \mu \mathrm{m}$ (Friess et al., 1980, 1982). 
The primary role of the placenta is to provide for fetal nutrition, gas exchange and waste removal throughout gestation (Dantzer, 1982; Munro, 1986). There are four main pathways whereby solutes can pass from maternal blood to fetal blood (Sibley et al., 1997). The first pathway is simple flow-limited diffusion. Molecules such as oxygen and carbon dioxide readily cross cell membranes and, therefore, their transfer from maternal to fetal circulation is limited only by the rate of delivery to the site of transfer (Björkman, 1973; Leiser and Dantzer, 1988; Sibley and Boyd, 1992). The second pathway is protein-mediated transport. The diverse transporter proteins involved can be active transporters or passive transporters, symporters or antiporters, or ion channels (Sibley et al., 1997). Finally, there are two types of transport of which the activity in the placenta is poorly understood: paracellular and endocytosisexocytosis (Dantzer, 1982; Friess et al., 1982; Sibley et al., 1997). Paracellular transfer involves transfer through the extracellular fluid surrounding the cells of the placenta. Endocytosis-exocytosis involves engulfing solutes into an endocytotic vesicle, vesicular transport through the cell and exocytotic expulsion at the opposite pole. Endocytosisexocytosis has been observed in pigs in structures referred to as transfer tubules (Sperhake, 1971 (in Friess et al., 1980); Friess et al., 1980, 1982; Dantzer, 1982). Simple flow-limited diffusion is regulated not only by the rate of maternal and fetal blood flows, but also by the arrangement of the endometrial and placental vasculature with respect to each other (Carter, 1989; Carter and Myatt, 1995). These arrangements are generally described by how closely they reflect particular fluid mechanical models, and include concurrent, crosscurrent and countercurrent exchange (Carter, 1989). Of these, concurrent exchange is least efficient $(50 \%$ theoretical maximal transfer), countercurrent exchange is most efficient ( $100 \%$ theoretical maximal transfer) and efficiency of crosscurrent exchange is between these two values (Carter, 1989). In pigs, placental transfer of freely diffusible nutrients appears to rely on a vascular anatomy that is either concurrent or possibly crosscurrent (Friess et al., 1982; Leiser and Dantzer, 1988). Transporter protein-mediated transfer relies on the density and relative activity of the transporters, and is generally not limited by the rate of blood flow. In pigs, protein-mediated transfer appears to be concentrated in the troughs of the chorionic folds (adjacent to the ridges of endometrial folds; Friess et al., 1980, 1982; Poston, 1997; Sibley et al., 1997). Transported solutes include, but are not limited to, glucose, amino acids and ions, such as sodium, potassium, calcium and protons (Davies, 1960; Battaglia, 1986; Faber and Thornburg, 1986; Lester, 1986; Sibley et al., 1997). In addition to transfer across the interface between the uterine luminal epithelium and chorionic epithelium, large macromolecules (for example, uteroferrin) produced in the endometrial glands are absorbed intact by the placental areolae (Perry, 1981; Friess et al., 1982; Roberts et al., 1986; Leiser and Dantzer, 1994).

By using the gross measurement of placental efficiency as an indicator of overall placental function (for example, diffusion, active transport, umbilical and uterine blood flow, surface area and areolae number), total function has been emphasized over component function. However, the component that may be most important, and into which further investigation has been initiated (see below), is the density of blood vessels in the chorioallantoic membrane (and associated endometrium). Placental efficiency is very low (0.06-0.15) from day 30 to day 40 of gestation (Spies et al., 1959; Knight et al., 1977; Wilson et al., 2000; Fig. 1), but begins to increase very rapidly by day 50 (that is, approximately threefold; 0.6 ) and continues to increase, although at a reduced rate, until term (Knight et al., 1974, 1977; Dalton and Knight, 1983; Wilson et al., 2000; Fig. 1). This pattern of increased placental efficiency is critical to the exponential growth of the fetal component of the conceptus with regard to limited growth of the placenta after day 70 of gestation. It would appear that there is a second inflection point in the placental efficiency curve as the animal nears term (Fig. 1). It is suggested that the increase in placental efficiency is attenuated by the secondary increase in placental mass from 


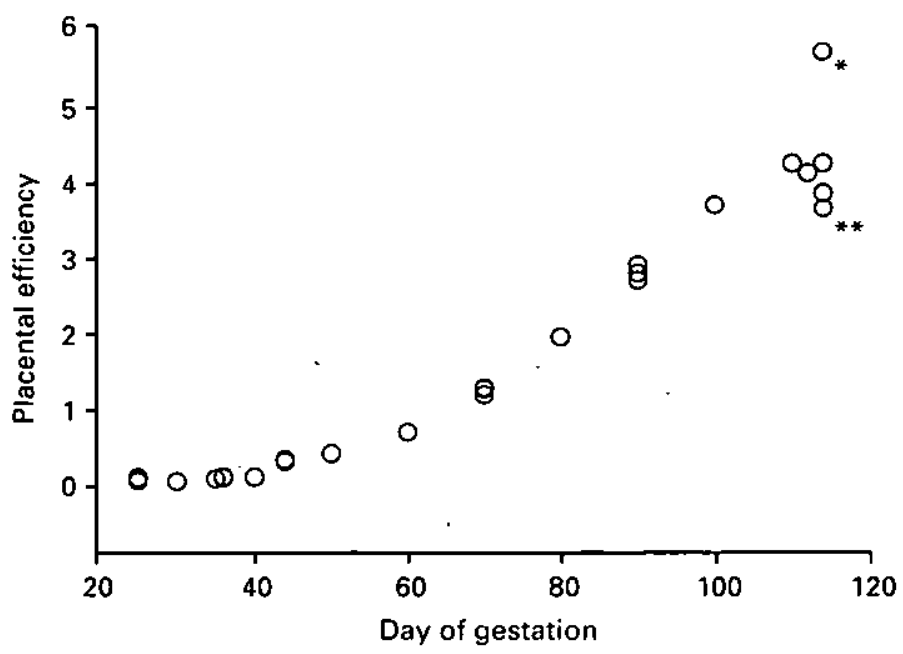

Fig. 1. Pattern of placental eifficiency (fetal weight:placental mass) throughout gestation in pigs. Data summarized from several sources (Spies et al., 1959; Knight et al., 1974, 1977; Dalton and Knight, 1983; Ford, 1997; Wilson et al., 1998, 1999a, 2000). *Individuals born to female pigs selected for greater than average placental efficiency. ${ }^{* *}$ Individuals born to female pigs selected for lower than average placental efficiency.

day 100 to day 110 of gestation to term. These data support the contention that the pig may be reaching a maximization of placental function coinciding with the end of gestation, which would probably be critical to the rapidity with which fetuses become nutritionally distressed in cases of delayed parturition.

\section{Variation in placental size and function}

The hallmark of placental efficiency is the marked variation that is present within a litter. This variation was characterized in an experiment using straight bred Yorkshire litters in which the umbilical cords of individual piglets were tagged at birth to allow piglets to be matched with their placentae. In eight litters, placental efficiency was $4.2 \pm 0.2$, which is very similar to that observed by Ford (1997) and Wilson et al. (1999a). However, the placental efficiency of individual conceptuses in all eight litters ranged from 2.7 to 7:4 (Wilson et al., 1999a), and in one litter from 3.8 to 7.4. In this initial study, and in several subsequent studies, variation in placental efficiency was not associated with variation in the body weight of the fetus (prenatally) or piglet (natally), but was negatively associated with variation in the mass of the placenta (Biensen et al., 1999; Wilson et al., 1999a, 2000). This finding was observed not only near term when fetal growth is at a maximum and probably close to the limit for placental function, but was also evident as early as day 25 of gestation (Wilson et al., 2000). Indeed, during the critical period between day 25 and day 45 of gestation when uterine capacity becomes limiting (that is, crowding reduces conceptus survival; Dziuk, 1968; Dhindsa and Dziuk, 1968; Fenton et al., 1972; Pope et al., 1972; Knight et al., 1977; Huang et al., 1987; Wilson et al., 2000), there is a negative association between placental mass and placental efficiency (Wilson et al., 2000). Furthermore, as uterine capacity becomes limiting, the number of viable conceptuses in a litter is no longer associated with ovulation rate and begins 
to be associated with the average placental efficiency for that litter (Wilson et al., 2000). As expected, as placental mass reached a plateau at about day 60 of gestation, and the fetus continued to grow, placental efficiency was $>1$ between day 60 and 70 of gestation (Fig. 1). Factors that result in variation in placental size have been investigated. Direct effects, generally via application of steroids during gestation, were examined by Spies et al. (1959), Knight et al. (1974), McGovern et al. (1981) and Wilson and Ford (2000). Indirect effects were observed by causing uterine crowding using superovulation, superinduction or unilateral hysterectomy-ovariectomy (Dhindsa and Dziuk, 1968; Dziuk, 1968; Fenton et al., 1972; Pope et al., 1972; Knight et al., 1977; Huang et al., 1987). Unfortunately, as variation in placental function per se was not the objective of these studies, only average placental efficiencies could be derived for treatment groups and the degree of variation within each litter was not evident. Treatment of sows with oestrogen, progestogen or a combination of both on different days of gestation can stimulate placental growth (Spies et al., 1959; Knight et al., 1974; McGovern et al., 1981; Wilson and Ford, 2000) and crowding can limit placental growth (Knight et al., 1974, 1977). However, neither steroid treatment nor uterine crowding appears to have much effect on placental efficiency during gestation (Spies et al., 1959; Knight et al., 1974, 1977; Dalton and Knight, 1983). It is suggested that placental efficiency is a unique trait of each individual conceptus and that treatments altering placental mass also alter fetal weight as a result of a fairly static functionality of an individual placenta. However, in contrast, in an experiment in which Meishan female pigs were treated with oestradiol on day 12 and day 13 , or on day 13 and day 14 of gestation, a $40 \%$ increase in placental mass was observed at day 312 of gestation (Wilson and Ford, 2000). In these animals, placental efficiency was reduced compared with that of untreated controls. Whether the ability to alter placental efficiency markedly in Meishan female pigs is a result of a breed difference or is related to the lack of a secondary increase in placental mass after day 100 of gestation has not been established.

As pigs have a diffuse epitheliochorial type of placentation, its function is thought of as blood flow-limited, meaning that nutrient and gas fluxes across the maternal placental interface are limited by the rates of uterine and umbilical blood flows. Placentae of Meishan pigs do not increase in size from mid- to late gestation, but in contrast to placentae of Yorkshire pigs, undergo a marked increase in the proliferation of blood vessels in the chorioallantoic membrane that is in close contact with the associated endometrial vasculature (Biensen et al., 1998; Wilson et al., 1998). The marked increase in the density of placental blood vessels may increase the rate of nutrient and waste product exchange per unit area of placental-endometrial interface (Biensen et al., 1998). Divergence in the strategy used to acquire the nutrients required by the developing fetus is most notable after day 70 of gestation when the fetus has grown to a size at which it begins to exert significant metabolic demands on the placenta (Biensen et al., 1998; Wilson et al., 1998). Between day 70 and day 110 of gestation, vascular density of the Meishan placenta increases twofold, whereas Yorkshire placental surface area increases by approximately $50 \%$; however, significant littermate variation was observed in both breeds (Biensen et al., 1998).

The potential role of placental-derived angiogenic factors in modulating placental efficiency has been investigated by Vonnahme et al. (2001). Vascular endothelial growth factor (VEGF) is a potent angiogenic and vascular permeability factor that is produced by the epithelium of both the placenta and endometrium during gestation in pigs (Winther et al., 1999; Vonnahme et al., 2001; Vonnahme and Ford, 2001). Expression of VEGF mRNA is relatively low during early gestation (that is, days $25-45$ ). At some time after day 45 of gestation (mid-way through the initial period of rapid placental growth), expression of VEGF mRNA continues to increase until term (Vonnahme et al., 2001). The potential significance of 
placental production of VEGF is evident by a positive correlation throughout gestation between the relative amount of mRNA being produced by a placenta and the density of blood vessels in the placenta (Vonnahme et al., 2001). Furthermore, there was a positive association between the relative amount of VEGF mRNA present in a placenta and the efficiency of that placenta (Vonnahme et al., 2001).

\section{Impact of placental efficiency on uterine capacity}

Several authors over the past 30 years have indicated that if the number of conceptuses surviving beyond day 18 of gestation is increased, the 'capacity' of the uterus will begin to have a negative impact on litter size at approximately day 30 of gestation (Fenton et al., 1972; Pope et al., 1972; Huang et al., 1987; Wilson et al., 2000). Development of the early conceptus was characterized in a commercial line of pigs that had a very high ovulation rate (> 26 oocytes), in which $40 \%$ of potential conceptuses were lost by day 25 (Wilson et al., 2000). Between day 25 and day 35 of gestation there was an additional loss of approximately four conceptuses on average, supporting the role of the uterus in limiting litter size, even in a case in which no experimental manipulation was needed to increase the number of potential conceptuses. Conventionally, this limitation has been viewed simply as the absolute number of conceptuses that can be supported to a defined point of gestation, most notably parturition (Fenton et al., 1972; Pope et al., 1972; Chistenson et al., 1987; Huang et al., 1987). This view of uterine capacity has been instrumental in the advancement of our understanding of components important for limiting litter size (Christenson et al., 1987; Vallet et al., 1996; Rohrer et al., 1999; Pearson et al., 2000). However, in light of recent data, a revision of the terminology used is important (Wilson et al., 1999a; Vallet et al., 2001). In particular, uterine capacity should be defined more correctly as the total amount of placental mass a pregnant female pig can support to term. Therefore, it will include both an endometrial surface area for contact component and a component related to the average efficiency of the placentae in that litter (Wilson et al., 1999a; Wilson and Ford, 2000). The uterine component of uterine capacity may not be adequately described strictly by a measure of surface area, but variation may occur in endometrial function per unit area. If so, a greater understanding of how to measure endometrial or uterine function and how it varies may allow for an even better understanding of how 'uterine capacity' is regulated and how it limits litter size.

\section{Heritability of placental efficiency}

Reproductive characteristics traditionally show a very low heritability. Indeed, it has been suggested by some authors that the critical nature of reproduction has resulted in the presence of a large number of genes that show few alleles and, therefore, have a low potential for selection. This modified view of uterine capacity was used to select male and female pigs of normal birth weight from within a herd that showed either greater than average or lower than average placental efficiency (Wilson et al., 1999a). When gilts selected for high placental efficiency that had been mated to boars selected for high placental efficiency farrowed, the placental masses of their piglets were $40 \%$ lower than those farrowed by low placental efficiency gilts mated to low placental efficiency boars (Fig. 1). The resultant realized heritability was 0.37 (Wilson et al., 1999a). More importantly, sows with high placental efficiency farrowed more than three live pigs per litter than did sows with low placental efficiency $(12.8 \pm 0.7$ versus $9.5 \pm 0.6$, respectively). Furthermore, similar decreases in placental mass and increases in litter size were observed for sows with high placental efficiency than in sows with low placental efficiency when mated to the same boars and allowed to farrow a second 
time (Wilson et al., 1999a). Vonnahme and Ford (2001) established that placentae of conceptuses resulting from mating boars and gilts selected for high placental efficiency have a greater placental expression of VEGF mRNA in addition to a greater placental efficiency, than conceptuses resulting from mating boars and gilts selected for low placental efficiency, with unselected controls being intermediate. Vallet et al. (2001) used gilts that were unilaterally hysterectomized-ovariectomized from lines selected for ovulation rate, uterine capacity or unselected controls and failed to find an increase in placental efficiency in those selected for uterine capacity (simply measured as number of conceputses) compared with controls. Vallet et al. (2001) observed an increase in placental efficiency in the line selected for ovulation rate. More importantly, in the 422 litters that were collected across all three lines, the heritability of placental efficiency was noteworthy for a reproductive trait $(0.29 \pm 0.08$; Vallet et al., 2001), particularly when compared with reported heritabilities for uterine capacity and litter size (0.09, Young et al., 1996; and 0.16, Hertzer et al., 1940, respectively).

\section{Conclusion}

A greater understanding of the physiological basis of traits such as litter size will probably result in more successful attempts to improve the character of interest through either alterations in management or genetic selection. The realization that gestation is an active and integrative process is key to furthering this understanding. Inherent variation as well as the apparent lack of plasticity in the relative efficiency of placental function in pigs is a critical component of uterine capacity. Such variation may explain why selection simply for the number of conceptuses present in a crowded uterus without regard to variation in placental efficiency has not been successful. In addition, an important concept of placental efficiency in pigs is the consistent lack of association with fetal or piglet weight and consistent negative association with placental mass. These associations indicate that either large or small fetuses or piglets can develop on small or large placentae, but that in general large placentae are relatively less efficient than smaller placentae. As we continue to develop and refine understanding of the reproductive biology of the pig, variation in the developmental regulation and final function of the placenta should provide an insight into conceptus loss after day 30 of gestation, as well as the size, number and potentially the uniformity of piglets at birth.

\section{References}

Battaglia FC (1986) Placental transport and utilization of amino acids and carbohydrates Federation Proceedings 45 2508-2512

Bazer FW, Thatcher WW, Martinat-Botte $F$ and Terqui $M$ (1988) Sexual maturation and morphological development of the reproductive tract in Large White and prolific Chinese Meishan pigs Journal of Reproduction and Fertility 83 723-728

Biensen NJ, Wilson ME and Ford SP (1998) Meishan and Yorkshire fetal and placental development in either a Meishan or Yorkshire uterus to days 70,90 and 110 of gestation Journal of Animal Science 76 2169-2176

Biensen NI, Haussmann MF, Lay DC, Jr, Christian LL and Ford SP (1999) The relationship between placental and piglet birth weights and growth traits Animal Science 68 709-715

Björkman $N$ (1965) On the fine structure of the porcine placental barrier Acta Anatomica 62 334-342

Björkman N (1973) Fine structure of the fetal-maternal area of exchange in the epitheliochorial and endotheliochorial types of placentation Acta Anatomica 86 1-22

Björkman $N$ and Dantzer $V$ (1987) Placentation. In Textbook of Veterinary Histology 3rd Edn pp 340-360 Eds H-D Dellmann and EM Brown. Lea and Febiger, Philadelphia

Carter AM (1989) Factors affecting gas transfer across the placenta and the oxygen supply to the fetus fournal of Developmental Physiology 12 305-322

Carter AM and Myatt L. (1995) Control of placental blood flow: workshop report Reproduction, Fertility and Development 7 1401-1406

Christenson RK (1993) Ovulation rate and embryonic survival in Chinese Meishan and white crossbred pigs Journal of Animal Science 71 3060-3066

Christenson RK, Leymaster KA and Young LD (1987) Justification of unilateral hysterectomy-ovariectomy as a model to evaluate uterine capacity in stvine Journal of Animal Science 65 738-744 
Corner GW (1923) The problem of embryonic pathology in mammals, with observations upon intrauterine mortality in the pig American fournal of Anatomy 31 523-545

Dalton DL and Knight JW (1983) Effects of exogenous progesterone and estrone on conceptus development in swine fournal of Animal Science 56 1354-1361

Dantzer $V(1982)$ Transíer rubules in the porcine placenta Biblotheca Anatomica 22 144-149

Dantzer V and Leiser R (1994) Initial vascularization in the pig placenta. I. Demonstration of nonglandular areas by histology and corrosion casts Anatomical Record 238 177-190

Davies I (1960) Survey of Research in Gestation and the Developmental Sciences pp 19-52. Williams and Wilkins, Baltimore

Dhindsa DS and Dziuk PJ (1968) Influence of varying the proportion of uterus occupied by embryos on maintenance of pregnancy in the pig Journal of Animal Science 27 668-672

Dziuk PJ (1968) Effect of number of embryos and uterine space on embryo survival in the pig Journal of Animal Science 27 673-676

Dziuk PJ (1987) Embryonic loss in the pig: an enigma. In Manipulating Pig Production pp 28-39 Eds IL Barnett, ES Batterham and GM Cronin. Australasian Pig Science Assoc, Werribee

Faber II and Thornburg KL (1986) Fetal nutrition: supply, combustion, interconversion and deposition Federation Proceedings 45 2502-2507

Fenton FR, Schwartz FL, Bazer FW, Robison OW and Ulberg LC (1972) Stage of gestation when uterine capacity limits embryo survival in gilts Journal of Animal Science 35 383-388

Ford SP (1997) Embryonic and fetal development in different genotypes in pigs fournal of Reproduction and Fertility Supplement 52 165-176

Foxcroft GR (1997) Mechanisms mediating nutritional effects on embryonic survival in pigs Journal of Reproduction and Fertility Supplement 52 47-61

Friess AE, Sinowatz F, Skolek-Winnisch $R$ and Träutner $W$ (1980) The placenta of the pig. I. Fine structural changes of the placental barrier during pregnancy Anatomy and Embryology 158 179-191

Friess AE, Sinowatz F, Slolek-Winnisch $R$ and Träutner $W$ (1982) Structure of the epitheliochorial porcine placenta Biblotheca Anatomica 22 140-143

Galvin JM, Wilmut I, Day BN, Ritchie $M$, Thomson $M$ and Haley CS (1993) Reproductive performance in relation to uterine and embryonic traits during early gestation in Meishan, Large White and crossbred sows Journal of Reproduction and Fertility $98377-384$

Grosser $O$ (1933) Human and comparative placentation: including the early stages of human development Lancet $111999-1001$

Hammond J (1914) On some factors controlling fertility in domestic animals journal of Agricultural Science 6 263-277

Hanly S (1961) Prenatal mortality in farm animals Journal of Reproduction and Fertility 2 182-194

Hertzer HO, Lambert WV and Zeller HH (1940) Influence of inbreeding and other factors on litter size in Chester White swine Circular-United States Department of Agriculture 570 1-10

Huang YT, Johnson RK and Eckardt GR (1987) Effect of unilateral hysterectomy and ovariectomy on puberty. Uterine size and embryo development in swine Journal of Animal Science 65 1298-1305

Klemcke HG and Christenson RK (1997) Porcine fetal and maternal adrenocorticotropic hormone and corticosteroid concentrations during gestation and their relation to fetal size Biology of Reproduction 57 99-106

Knight JW, Bazer FW and Wallace HD (1974) Effect of progesterone induced increase in uterine secretory activity on development of the porcine conceptus journal of Animal Science 39 743-746

Knight JW, Bazer FW, Thatcher WW, Franke DE and Wallace HD (1977) Conceptus development in intact and unilaterally hysterectomized-ovariectomized gilts: interrelations among hormonal status, placental development, fetal fluids and fetal growth journal of Animal Science 44 620-637

Lawrence I (1993) By the year 2000: more pigs from fewer sows National Hog Farmer 12 January 22-24

Lee GJ, Ritchie $M$, Thomson $M$, MacDonald AA, Blasco A, Santacreu MA, Argente MJ and Haley CS (1995) Uterine capacity and prenatal survival in Meishan and Large White pigs Animal Science $60471-479$

Leiser $\mathbf{R}$ and Dantzer $\mathbf{V}(1988)$ Structural and functional aspects of porcine placental microvasculature Anatomy and Embryology 177 409-419

Leiser $R$ and Dantzer V (1994) Initial vascularisation in the pig placenta. II. Demonstration of gland and areolagland subunits by histology and corrosion casts Anatomical Record 238 236-334

Lester GE (1986) Cholecalciferol and placental calcium transport Federation Proceedings 45 2524-2526

McGovern PT, Morcom CB, de Sa WF and Dukelow WR (1981) Chorionic surface area in conceptuses from sows treated with progesterone and oestrogen during early pregnancy Journal of Reproduction and Fertility 61 $439-442$

Munro HN (1986) Role of the placenta in ensuring fetal nutrition Federation Proceedings 45 2500-2501

Pearson PL, Smith TP, Sonstegard TS, Klemcke HG, Christenson RK and Vallet JL (2000) Porcine erythropoietin receptor: molecular cloning and expression in embryonic and felal liver Domestic Animal Endocrinology 19 25-38

Perry IS (1954) Fecundity and embryonic mortality in pigs Journal of Embryology and Experimental Morphology 2 308-322

Perry IS (1981) The mammalian fetal membranes fournal of Reproduction and Fertility 62 321-335

Perry IS and Rowlands IW (1962) Early pregnancy in the pig Journal of Reproduction and Fertility 4 i $75-188$

Pomeroy RW (1960) Infertility and nconatal mortality in the sow. III. Neonatal mortality and foetal development Journal of Agricultural Science 54 31-56

Pope WF (1994) Embryonic mortality in swine. In Embryonic Mortality in Domestic Species pp 53-77 Eds MT Zavy and RD Geisen. CRC Press, Boca Raton 
Pope CE, Christenson RK, Zimmerman-Pope VA and Day BN (1972) Eiffect of number of embryos on embryonic survival in recipient gilts fournal of Animal Science 35 805-811

Poston L (1997) The control of blood flow to the placenta Experimental Physiology 82 377-387

Reynolds LP and Redmer DA (1995) Utero-placental vascular development and placental function journat of Animal Science 73 1839-1851

Rivera RM, Youngs CR and Ford SP (1996) A comparison of the number of inner cell mass and trophectoderm cells of preimplantation Meishan and Yorkshire pig embryos at similar developmental stages fournal of Reproduction and Fertility 106 111-116

Roberts RM, Raub TJ and Bazer FW (1986) Role of uteroferrin in transplacental iron transport in the pig Federation Proceedings 45 2513-2518

Rohrer GA, Ford IJ, Wise TH, Vallet JL and Christenson RK (1999) Identification of quantitative trait loci affecting female reproductive traits in a multigeneration Meishanwhite composite swine population Journal of Animal Science 77 1385-1391

Scofield AM (1972) Embryonic mortality. In Pig Production pp 367-383 Ed. DJA Cole. Butterworths, London

Sibley CP and Boyd RDH (1992) Mechanisms of transfer across the human placenta. In Fetal and Neonatal Physiology pp 62-74 Eds RA Polin and WW Fox. WB Saunders, Philadelphia

Sibley C, Glazier I and D'Souza S (1997) Placental transporter activity and expression in relation to fetal growth Experimental Physiology 82 389-402

Sperhake B (1971) Zur Durchlässigkeit der Placenta des Schweines - Eine Literaturstudie Inaug Diss Hannover

Spies HG, Zimmerman DR, Self HL and Casida LE (1959) The effect of exogenous progesterone on formation and maintenance of the corpora lutea and on easly embryo survival in pregnant swine fournal of Animal Science 18 163-172

Vallet IL, Christenson RK and McGuire WJ (1996) Association between uteroferrin, retinol-binding protein, and transferrin within the uterine and conceptus compartments during pregnancy in swine Biology of Reproduction 55 1172-1178

Vallet JL, Leymaster KA, Cassady JP and Christenson RK (2001) Are hematocrit and placental selection tools for uterine capacity in swine? Journal of Animal Science Supplement 7964 (Abstract)

Vonnahme KA and Ford SP (2001) Selection for increased placental efficiency (PE) results in increased placental expression of vascular endothelial growth factor (VEGF) in the pig Journal of Animal Science Supplement 7964 (Abstract)
Vonnahme KA, Wilson ME and Ford SP (2001) Role of vascular endothelial growth factor in modulating placental/endometrial vascularity in the pig Biology of Reproduction $641821-1825$

Wigmore PKC and Strickland NC (1985) Placental growth in the pig Anatomy and Embryology 173 263-268

Wilson ME and Ford SP (1997) Differences in trophectoderm mitotic rate and P450 $17 \alpha$-hydroxylase expression between late preimplantation Meishan and Yorkshire conceptuses Biology of Reproduction 56 380-385

Wilson ME and Ford SP (2000) Effect of estradiol-178 administration during the time of conceptus elongation on placental size at term in the Meishan pig Journal of Animal Science 78 1047-1052

Wilson ME, Biensen NJ, Youngs CR and Ford SP (1998) Development of Meishan and Yorkshire littermale conceptuses in either a Mcishan or Yorkshire uterine environment to day 90 of gestation and to term Biology of Reproduction $58905-910$

Wilson ME, Biensen NJ and Ford SP (1999a) Novel insight into the control of litter size in the pig, using placental efficiency as a selection tool journal of Animal Science 77 1654-1658

Witson ME, Vonnahme KA and Ford SP (1999b) Use of asynchronous embryo Iransfer to investigate the role of uterine-embryo timing on placental size journal of Animal Science Supplement 77222 (Abstract)

Wilson ME, Vonnahme KA, Foxcroft GR, Gourley G, Wolff T, Quirk-Thomas M and Ford SP (2000) Characteristics of the reproductive biology of multiparous sows from a commercially retevant population lournal of Animal Science Supplement 78213 (Abstract)

Winther $H$, Ahmed A and Dantzer V (1999) Immunohistochemical localization of vascular endothelial growth factor (VEGF) and its two specific receptors, Flt-1 and $K D R$, in the porcine placenta and non-pregnant uterus Placento $2035-43$

Young LD, Leymaster KA and Christenson RK (1996) Opportunities for indirect selection for uterine capacity of swine fournal of Animal Science Supplement 74119 (Abstract)

Youngs CR, Ford SP, McGinnis LK and Anderson LH (1993) Investigation into the control of litter size in stvine. I. Comparative studies on in vitro development of Meishan and Yorkshire preimplantation embryos Journal of Animal Science 71 1561-1565

Youngs CR, Christenson LK and Ford SP (1994) Investigations into the control of litter size in swine. III. A reciprocal embryo transier study of early conceptus development journal of Animal Science 72 725-731 